\title{
Cancer Associated Fibroblasts Derived from Pancreatic Adenocarcinoma and Their Role in Cell Migration
}

\author{
ELLEN VON HOERSCHELMANN, CHRISTOPHER C. M. NEUMANN, \\ MATTHAUS FELSENSTEIN, JULIA GOGOLOK, ANJA REUTZEL-SELKE, \\ IGOR M. SAUER, JOHANN PRATSCHKE, MARCUS BAHRA and ROSA B. SCHMUCK \\ Department of Surgery, Experimental Surgery, Campus Charité Mitte, Campus Virchow Klinikum, \\ Charité - Universitätsmedizin Berlin, Corporate Member of Freie Universität Berlin, \\ Humboldt-Universität zu Berlin, and Berlin Institute of Health, Berlin, Germany
}

\begin{abstract}
Background/Aim: Pancreatic ductal adenocarcinoma (PDAC) shows poor survival and early systemic dissemination. Cancer associated fibroblasts (CAFs) enhance migration and invasion of cancer cells. We aimed to investigate the role of $C A F s$ in cell migration and their underlying paracrine effects. Materials and Methods: Using Transwell ${ }^{\circledR}$ migration assays, PDAC cells (PANC-1) and three distinct types of fibroblasts were analyzed: CAFs, genetically transformed human foreskinfibroblasts (BJeLR), and non-transformed human foreskinfibroblasts (VH7). IL6 in the culture supernatant was measured to investigate paracrine communication in monocultures and direct/indirect cocultures. Results: CAFs showed a significantly higher capacity to migrate in vitro when compared to benign fibroblasts $(p=0.009)$. They also facilitated the migration of PDAC cells in coculture $(p=0.001)$. Neither BJeLR, nor VH7 displayed such features. This was accompanied by a significant increase in IL-6 when CAFs were cocultured with PANC-1 ( $p=0.009)$. Conclusion: $C A F$ s are a key element of intra-tumoral migration and should be further investigated as a potential therapeutic target.
\end{abstract}

Patients with pancreatic ductal adenocarcinoma (PDAC) display poor 5-year survival rates of approximately $9 \%$, concomitant with steadily increasing incidence rates (1). In addition, pancreatic carcinoma cells tend to metastasize at a very early stage (2) and when diagnosed, about $53 \%$ of the

This article is freely accessible online.

Correspondence to: Rosa B. Schmuck, Department of Surgery, Charité - Universitätsmedizin Berlin, Charité Platz 1, 10117 Berlin, Germany. Tel: +49 30450652184, Fax: +49 304507652184, e-mail: rosa.schmuck@charite.de

Key Words: Pancreatic cancer, cancer associated fibroblasts, migration, paracrine communication. patients with PDAC present with systemic dissemination (3). Early metastasis limits surgical treatment options and due to greatly ineffective chemotherapies, the patient's overall survival drops significantly (4). Therefore, underlying mechanisms that cause early metastasis are of major interest.

A dense and fibrotic desmoplastic stroma is characteristic of the PDAC. The pancreatic tumor microenvironment largely consists of inflammatory and immune cells, extracellular matrix and foremost cancer-associated fibroblasts (CAFs) (5, $6)$, which all play a significant role in tumor spread and therapy resistance (7-11). Each of the cell types have multiple functions, some of which help the pancreatic cancer cells sustain and enhance their malignant potential. Here, CAFs are of particular interest, exhibiting functions that enable and enhance the migration of cancer cells and promote a proinvasive tumor environment $(5,12-15)$.

CAFs originate from various pancreatic cell types, such as pancreatic stellate cells, resident fibroblasts, bone marrow derived cells (BMDC) and epithelial cells (5). Even in the early stages of pancreatic cancer development/carcinogenesis, carcinoma cells establish a specific cancer microenvironment, which activates fibroblasts (16-19). Activated CAFs are characterized by unique expression of $\alpha$-SMA, in addition to Vimentin and GFAP $(11,20)$.

CAFs are able to communicate with the cells in their direct tumor microenvironment by direct cell-cell contact as well as in a paracrine manner (21). Hereto, CAFs can secrete pro-inflammatory cytokines such as IL1 $\beta$, IL6, IL10, and TNFalpha $(22,23)$. In particular, IL6, which acts in the IL6/STAT3 pathway, can be regarded as a pivotal actor initiating and promoting carcinogenesis, while orchestrating the epithelial-mesenchymal transition and metastasis in pancreatic cancer (24-30). Moreover, increased IL6 serum levels in the clinical setting have been associated with liver metastasis, advanced stage cancer and limited survival (31).

Here, we focused on further investigating the underlying paracrine effects of primary pancreatic cancer fibroblasts on 
Table I. Specifications of the donors of patient derived cancer associated fibroblasts (CAFs). All CAFs were obtained from pancreatic adenocarcinoma specimens.

\begin{tabular}{lccccccc}
\hline Patient & Age & Gender & Tumor type & T Stage & N Stage & Grade & Passages used for analysis \\
\hline 1 & 53 & $\mathrm{~m}$ & Adenocarcinoma & 2 & 2 & G3 & $2,3,5$ \\
2 & 57 & $\mathrm{w}$ & Adenocarcinoma & 2 & 1 & $\mathrm{G} 2$ & $2,3,4$ \\
3 & 52 & $\mathrm{w}$ & Adenocarcinoma & $3 \mathrm{~b}$ & 1 & $\mathrm{G} 3$ & 1,2 \\
\hline
\end{tabular}

migration as a key mechanism of metastasis in the PDAC microenvironment (32). We used a Transwell ${ }^{\circledR}$ migration assay in which pancreatic cancer cells (PANC-1) and fibroblasts were spatially separated but able to communicate in a paracrine manner.

In search of the molecular mechanisms by which CAFs potentially impact and somehow maintain their procancerous effects during in vitro cultures, genetic alterations were also investigated $(33,34)$. Notably, down-regulation of p53 may distinguish CAFs from other fibroblasts (35). Additionally, conditioned medium from fibroblasts with down-regulated p53 expression was shown to increase tumor cell migration in vitro (36).

In order to investigate the pro-invasive effects of CAFs, we compared CAFs isolated directly from resected pancreatic cancer specimens with the genetically transformed human foreskin derived fibroblasts BJeLR (BJ fibroblasts transformed with hTERT, genomic SV40 LT and ST oncoproteins, and oncogenic HRASV12). These fibroblasts were immortalized via an hTERT vector by lentiviral transfection, but also equipped with the oncogenic SV40T and HRASV12, altogether suppressing the cell cycle control protein p53 (37). Non-transformed human foreskin fibroblasts (VH7) served as a non-malignant control.

\section{Materials and Methods}

Patient derived cell lines. Three patients who suffered from resectable PDAC and gave informed consent before operation served as tissue donors. Exclusion criteria were pregnancy and age under 18 years. Analyses were conducted following approval from the institutional review board (EA1/292/16) and in accordance with the Helsinki Declaration of 1975.

Cell culture. Three different types of fibroblasts; primary pancreatic CAFs, BJeLR, VH7 and a pancreatic cancer cell line (PANC-1) were used for the experiments. In addition, CAFs were derived from the tumor tissues of three individuals suffering from PDAC (Table I). Derivation protocols were described previously (38). In brief, the tissue was dissociated mechanically, rinsed with cell culture medium and seeded into cell culture flasks. CAFs were characterized using immunohistochemical staining following established protocols (39), which used vimentin-rabbit polyclonal IgG antibody (Santa Cruz Biotechnology, CA, USA), monoclonal mouse anti-glial fibrillary acidic protein (GFAP) antibody (Sigma Aldrich, St. Louis, MO, USA) and monoclonal mouse anti-actin $\alpha$-smooth muscle ( $\alpha$-SMA) antibody (Sigma Aldrich). Primary fibroblast cultures were continued when mesenchymal origin with high purity had been validated. VH7 is a non-transformed human foreskin cell line that served as a nonmalignant control, as previously described (40). BJeLR cells are human foreskin fibroblasts transformed with a vector containing the human telomerase reverse transcriptase (hTERT), genomic SV40 LT and ST oncoproteins and oncogenic HRASV12. They were obtained directly from Hahn et al. and kindly provided by Prof. Dr. rer. nat. Reinhold Schäfer (Charité Universitätsmedizin Berlin) (37). PANC1 is a commercially available cell line of pancreatic adenocarcinoma. All cell lines were cultured in RPMI 1640 supplemented with $10 \%$ fetal bovine serum, penicillin and streptomycin and incubated at $37^{\circ}$ in humidified air containing $5 \% \mathrm{CO}_{2}$.

For verification of the correct identity and origin of the cell lines, cell authentication was carried out by DNA fingerprinting, which used 8 different and highly polymorphic short tandem repeat (STR) loci. In addition, all samples were tested for the presence of mitochondrial DNA sequences from rodent cells. Analyses were carried out by Leibniz-Institute German Collection of Microorganisms and Cell Cultures.

Migration assay. To analyze the migration of cells, standardized cell migration assay was performed, using $8 \mu \mathrm{m}$ pore Transwell ${ }^{\circledR}$ cell culture inserts (Falcon ${ }^{\circledR}$, Cat \#353097) in a 24-well plate. For the monoculture setup, cells were trypsinized and $10^{4}$ cells were seeded into the upper chamber of the Transwell ${ }^{\circledR}$ cell culture inserts in fetal bovine serum (FBS) free cell culture medium. The bottom chamber was filled with cell culture medium containing FBS. In an indirect co-culture setup, $5 \times 10^{4}$ cells were additionally seeded into the lower chamber. After $24 \mathrm{~h}$ incubation, the Transwell ${ }^{\circledR}$ membranes were washed and stained with $0.05 \%$ Crystal violet for $20 \mathrm{~min}$.

The membrane was captured at $5 \times$ magnification by analyzing four visual fields per sample. The results were displayed as mean pixels/area and counted via Fiji using a macro for the threshold and pixel analysis function as described previously $(41,42)$.

ELISA. Cell culture supernatant was collected from a CAF and PANC-1 monoculture and co-culture set-up in a standardized fashion, as previously described (38). The levels of IL6 in the medium were measured using a Human IL-6 ELISA set (BD OptEIA ${ }^{\mathrm{TM}}$, San Jose, CA, USA, Cat\# 555220). The ELISAs were performed according to the manufacturer's instructions and the levels of IL6 were normalized to the number of cells used in each culture.

Statistical analysis. Statistical analyses were performed with GraphPad Prism (version 8.4.0 for MacOS, GraphPad Software, San 

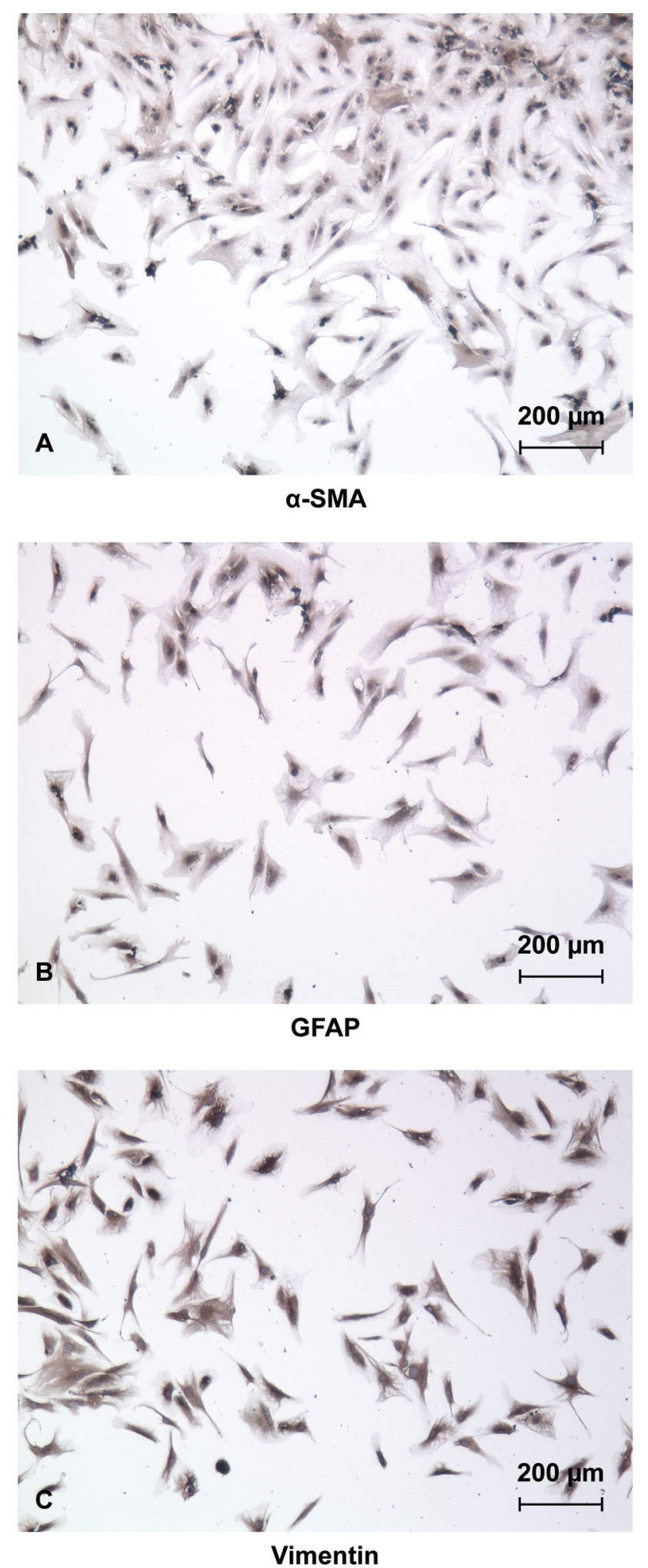

Figure 1. Immunohistochemistry staining of one representative cell line of primary pancreatic cancer associated fibroblast (CAF), using $\alpha-S M A$ $(A)$, Vimentin $(B), G F A P(C)$. All patient-derived primary pancreatic cancer fibroblasts were characterized as CAFs for all sources.

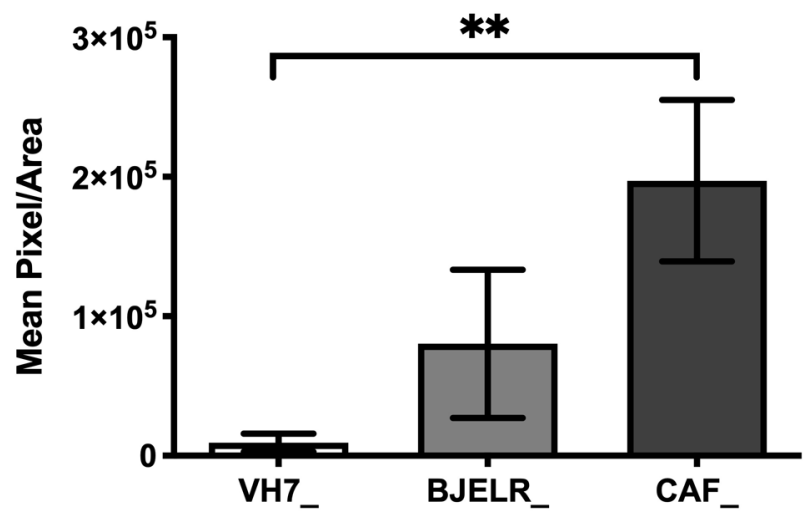

Figure 2. Fibroblast migration: The migration of $V H 7(n=3), B J E L R$ $(n=3)$ and primary cancer associated fibroblast $(C A F)(n=9)$ was observed in a monoculture setup during a period of $24 \mathrm{~h}$. All fibroblasts showed a capacity of migration. Primary pancreatic CAFs migrate significantly more than benign fibroblasts $(V H 7) .{ }^{* *} p \leq 0.01$.

Diego, CA, USA). For the statistical analysis all data obtained from the migration assays and the cell culture supernatant analysis was tested without following the non-Gaussian distribution. To test more than two groups, the Kruskal-Wallis test was performed followed by a post-hoc Dunn's multiple comparisons test. When significance correlation was tested, results were followed by a Mann-Whitney $U$ test for testing independent variables in a pairwise comparison. For matching pairs, a Wilcoxon signed-rank test was conducted. In all tests performed, $p<0.05$ characterized significant correlations.

\section{Results}

Characterization of CAFs. CAFs of three patients suffering from PDAC were isolated (Table I). Before conducting additional studies, we ensured that the isolated fibroblasts from the three individuals could be defined as CAFs, all coexpressing $\alpha$-SMA, Vimentin and GFAP (Figure 1).

CAFs show significant capacity for migration. To study the migration capacity of fibroblasts, non-patient derived fibroblast cell lines VH7 and BJeLR as well as the primary pancreatic CAF were analyzed by conducting a standardized migration assay on monocultures. All three types of fibroblasts maintained a reproducible degree of migration (Figure 2). However, there was a significant difference in the capacity of self-induced cell migration. Multiple comparison analysis revealed a remarkable difference regarding the migration capacity in monoculture between $\mathrm{VH} 7$ and $\mathrm{CAF}$ $(p=0.018$, Table II) and was confirmed by pairwise comparison $(p=0.009$, Table II).

Effect of PANC-1 on fibroblast migration. In the next set of experiments, we analyzed the migration characteristics of the included types of fibroblasts in indirect coculture with the 
Table II. Overview of the analysis results. Listed are the conducted statistical tests with the corresponding $p$ values based on data obtained from the measurements presented in this study. PANC- $1=P$.

\begin{tabular}{|c|c|}
\hline Migration fibroblasts (monoculture) & $p$-Value \\
\hline Kruskal-Wallis test & 0.007 \\
\hline \multicolumn{2}{|l|}{ Dunn's multiple comparisons test } \\
\hline VH7_vs. BJeLR_ & 0.432 \\
\hline $\mathrm{VH}_{-}$vs. $\mathrm{CAF}_{-}$ & 0.018 \\
\hline $\mathrm{BJeLR}_{-} v s . \mathrm{CAF}_{-}$ & 0.998 \\
\hline \multicolumn{2}{|l|}{ Mann Whitney test } \\
\hline $\mathrm{VH} 7 \_$vs. $\mathrm{CAF}_{-}$ & 0.009 \\
\hline $\begin{array}{l}\text { Migration of fibroblasts } \\
\text { (indirect co-culture with PANC-1) }\end{array}$ & $p$-Value \\
\hline Kruskal-Wallis test & 0.211 \\
\hline \multicolumn{2}{|l|}{ Dunn's multiple comparisons test } \\
\hline VH7_vs.VH7_P & $>0.999$ \\
\hline $\mathrm{VH}_{-}{ }_{-} v s . \mathrm{BJeLR}$ & $>0.999$ \\
\hline VH7_vs. BJeLR_P & $>0.999$ \\
\hline $\mathrm{VH}_{-}$vs. CAF_- & $>0.999$ \\
\hline $\mathrm{VH}_{-}^{-}$vs. CAF_P & 0.238 \\
\hline VH7_Pvs. BJeLR_ & $>0.999$ \\
\hline VH7_P vs. BJeLR_P & $>0.999$ \\
\hline VH7_P vs. CAF_- & $>0.999$ \\
\hline VH7_P vs.CAF_P & $>0.999$ \\
\hline BJeLR_vs. BJeLR_P & $>0.999$ \\
\hline $\mathrm{BJeLR}_{-}$ss. CAF_ & $>0.999$ \\
\hline BJeLR_vs. CAF_P & $>0.999$ \\
\hline BJeLR_P $v s . \mathrm{CAF}_{-}$ & $>0.999$ \\
\hline BJeLR_P vs. CAF_P & $>0.999$ \\
\hline $\mathrm{CAF}_{-} v s . \mathrm{CAF}_{-} \mathrm{P}$ & $>0.999$ \\
\hline \multicolumn{2}{|l|}{ Wilcoxon matched-pairs signed rank test } \\
\hline VH7_vs. VH7_P & 0.250 \\
\hline BJeLR_vs. BJeLR_P & 0.500 \\
\hline CAF_vs. CAF_P & 0.098 \\
\hline
\end{tabular}

established PDAC cell line PANC-1 (Figure 3). We were not able to detect any significant effect of PANC-1 cocultures on the migration of studied fibroblasts when compared to migration in monoculture. In pairwise comparison however, we observed a clear trend of increasing CAF migration when cocultured with PANC-1 when compared to the monoculture $(p=0.098$, Table II).

CAFs increase migration of PANC-1 in indirect co-culture. We subsequently analyzed the effect of fibroblasts on the migration of PANC-1. For this, PANC-1 cells were studied either in monoculture or in indirect coculture with $\mathrm{VH} 7$, BJeLR and CAFs, respectively (Figure 4). PANC-1 cells showed a consistent and reproducible migration in monoculture (Figure 5). When cultured in indirect coculture

\begin{tabular}{|c|c|}
\hline $\begin{array}{l}\text { Migration PANC-1 } \\
\text { (indirect co-culture with fibroblasts) }\end{array}$ & $p$-Value \\
\hline $\begin{array}{l}\text { Kruskal-Wallis test } \\
\text { Dunn's multiple comparisons test }\end{array}$ & 0.064 \\
\hline $\mathrm{P}_{-}$vs. P_VH7 & 0.629 \\
\hline $\mathrm{P}_{-} v s . \mathrm{P}_{-} \mathrm{BJ} J \mathrm{LR}$ & $>0.999$ \\
\hline $\mathrm{P}_{-} v s . \mathrm{P}_{-} \mathrm{CAF}$ & 0.025 \\
\hline $\begin{array}{l}\text { Mann Whitney test } \\
\text { P_vs. }_{-} \text {_CAF }\end{array}$ & 0.001 \\
\hline IL6 concentration in medium supernatant & $p$-Value \\
\hline Kruskal-Wallis test & 0.001 \\
\hline Dunn's multiple comparisons test & \\
\hline CAF Monoculture vs. Indirect Coculture & 0.269 \\
\hline CAF Monoculture vs. Direct Coculture & 0.022 \\
\hline CAF Monoculture vs. PANC-1 Monoculture & 0.765 \\
\hline Indirect Coculture vs. Direct Coculture & 0.940 \\
\hline Indirect Coculture vs. PANC-1 Monoculture & 0.020 \\
\hline Direct Coculture vs. PANC-1 Monoculture & 0.002 \\
\hline Mann Whitney test & \\
\hline CAF Monoculture vs. Indirect Coculture & 0.005 \\
\hline CAF Monoculture vs. Direct Coculture & 0.009 \\
\hline Indirect Coculture vs. Direct Coculture & 0.012 \\
\hline CAF Monoculture vs. PANC-1 Monoculture & 0.009 \\
\hline
\end{tabular}

Bold values indicate statistical significance.

with the two non-patient derived tumor associated cell-lines VH7 and BJeLR, we did not detect any change in cell migration of PANC-1 cells. After coculturing with CAFs however, the migration of PANC-1 cells increased significantly, when tested with multiple comparison $(p=0.025$, Table II) and in pairwise correlation ( $p=0.001$, Table II).

Significant increase of IL6 in CAF-PANC-1 co-culture. To further understand the underlying paracrine effects on tumor cell migration, we analyzed the IL6 concentration in the supernatant of PANC-1- and CAF monocultures as well as in direct and indirect co-cultures (Figure 6). Unlike CAFs, PANC-1 cells did not show secretion of IL6. We therefore concluded that in all cell culture setups, IL6 is secreted solely from CAFs. Further, PANC-1 cell presence in the coculture setups led to a significant increase in IL6 secretion by the CAFs both in indirect coculture (multiple comparison: $p=0.064$, pairwise comparison: $p=0.005$, Table II) as well as in direct coculture (multiple comparison: $p=0.0026$, pairwise comparison: $p=0.009$, Table II). 


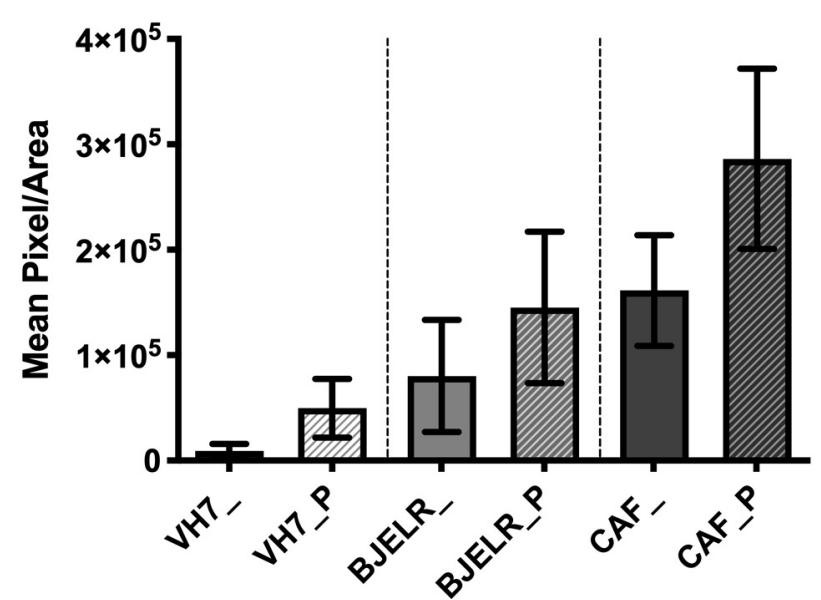

Figure 3. Migration of fibroblast cell lines and primary cancer associated fibroblasts (CAFs) in indirect coculture with PANC-1. The fibroblasts VH7 $(n=3), \operatorname{BJELR}(n=3)$ and $C A F(n=9)$ were cultured in mono-culture versus indirect coculture with PANC-1 $(P)$ and after $24 \mathrm{~h}$ incubation, the migration of the fibroblasts was analyzed. We could demonstrate a trend of an increased migration when CAFs were cocultured with PANC-1 (CAF_P). Cell-name followed by the character "_" were in the top chamber of the transwell set-up, cell-name preceding the character "_" were in the bottom chamber of the transwell set-up.

\section{Discussion}

In this study, we aimed to better understand the impact of CAFs on pancreatic carcinoma cells using PANC-1 carcinoma cell line, as well as primary and established cell culture models of human fibroblasts, that mimic the tumor microenvironment of PDAC (43). There is an ongoing debate about whether CAFs actually possess an innate malignant potential (44). Recent studies by our group have already demonstrated that CAFs can confer chemoresistance when co-cultured in vitro (38). In the present study, we compared different types of human fibroblasts: patient derived malignant CAFs, fibroblasts with activated oncogenes and inhibited tumor suppressors (BJeLR), and benign fibroblasts. We observed that CAFs exhibit malignant features as they migrate unlike other fibroblasts and also, exclusively promote the migration of PDAC cells. Thus, they evidently play an active role in cell migration and we would therefore refute their former characterization as 'bystander cells' (45).

Genetic alterations in the RAS family and p53 have been discovered to be critical in pancreatic cancer development and progression (46). This has been mainly established on the duct/acinar cell fraction. Stromal cells have not yet been analyzed regarding their RAS and p53 characteristics. Lately, it has been theorized that these alterations may play a role in CAF function as well. Several studies have detected a p53

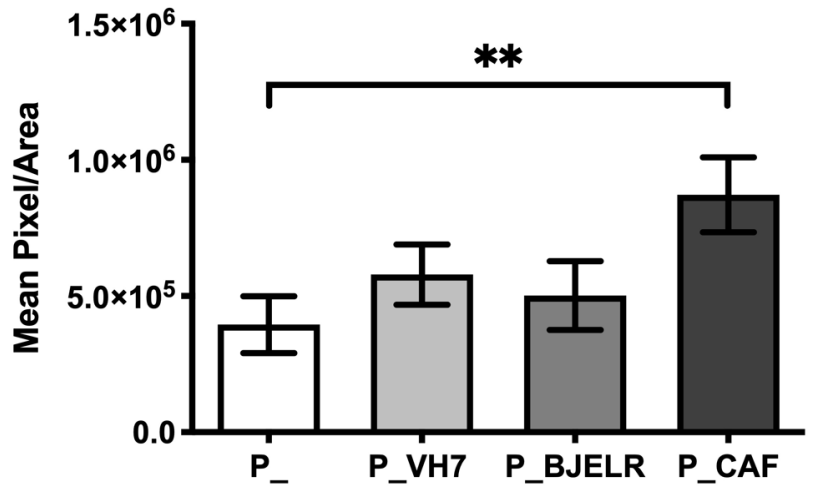

Figure 4. Migration of PANC-1. The migration of PANC-1 (P) after 24 $h$ was observed in monoculture $(n=10)$ and in indirect coculture with different types of fibroblasts (VH7, $n=3), B J e L R(n=5)$ and cancer associated fibroblast (CAF) ( $n=5)$. Migration of PANC-1 increases significantly when in indirect coculture with primary pancreatic cancer fibroblasts $\left(P_{-} C A F\right)$. Cell-name followed by the character “_" were in the top chamber of the transwell set-up, cell-name preceding the character "_" were in the bottom chamber of the transwell set-up.

alteration in CAFs that modify their functioning and enhance the malignant features of their respective cancers (47). This non-autonomous effect is initiated via regulation of cancerpromoting genes and secreted proteins $(35,48)$, also in line with a different study, which revealed a direct link between cancer cells and CAFs in chemotherapy response of lung cancers based on p53 dependence (49).

$R A S$ mutations (particularly KRAS) are known to be oncogenic, and in combination with $p 53$ alterations suffice to develop tumors in both, human and genetically engineered mouse models (e.g. KPC mice) (50-52). Moreover, HRAStransformed mouse fibroblasts show increased genomic instability and altered chromosomal protein phosphorylation (53). Murine $R A S$ mutated fibroblasts generated a high local level of proteins involved in tumor growth and angiogenesis (54). Studies suggest that a RAS induced activation of CAF might be one important underlying mechanism causing this (55). We therefore evaluated the effect of HRAS mutated and p53 suppressed fibroblasts (BJELR) in our experiments. Remarkably, we were unable to detect an increased capacity for cell migration by BJeLR fibroblasts, nor found evidence they could enhance the migration of PDAC cells in indirect co-cultures.

Several limitations of this study should be noted: First of all, we chose a two-dimensional cell culture setup in our experiments. For this reason, important factors that might influence cell migration, including fiber composition and alignment of the extracellular matrix scaffold, were not considered. However, the setup essentially facilitated high reproducibility of in vitro assays, while considering the 

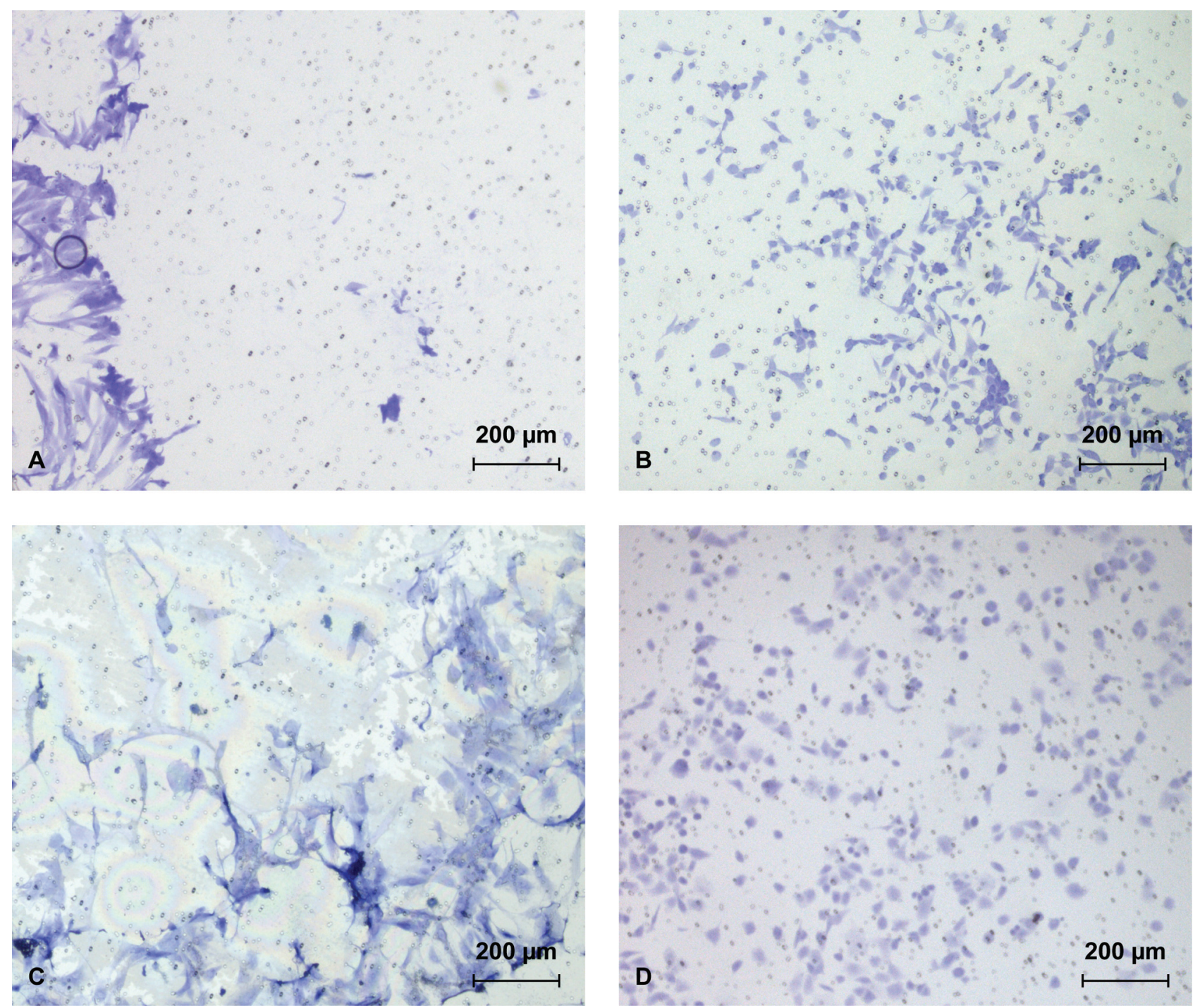

Figure 5. Staining of migrated cells. The three different types of fibroblasts VH7 (A), BJeLR (B), cancer associated fibroblast (CAF) (C) and PANC1 cells $(D)$ were stained following 24 h migration through 8 um pores (Transwell ${ }^{\circledR}$-based migration assay).

limited number of available patient derived fibroblasts. This was in part due to the fastidious derivation process with a relatively slow doubling time and early senescence of mesenchymal cells in the primary tumor. However, we believe that working with patient derived primary CAFs is essential, in order to investigate and model the biology of the pancreatic tumor microenvironment. This could be supported by our findings that neither benign, nor genetically modified fibroblasts show significant effect on the migration capacity of PDAC cells. In addition, we focused solely on CAFs, while other stromal components like immune cells or endothelial cells were not included in the analysis. Also, the interaction with vascular structures may play an important role in the early steps of metastasis. For this reason, experiments that include the investigation of other cell components of the pancreatic cancer microenvironment are warranted.

CAFs in PDAC are known to express $\alpha$-SMA, a microfilament forming protein particularly active in activated myofibroblasts (56). All CAFs analyzed in the present study were verified to express $\alpha$-SMA (Figure 1). Activated CAFs are known to produce excessive amounts of ECM in the presence of carcinoma cells $(57,58)$. However, the increase in migration detected in our experiments must be an additional paracrine effect as there was no direct cell-cell contact with cancer cells. In the densely packed desmoplastic 


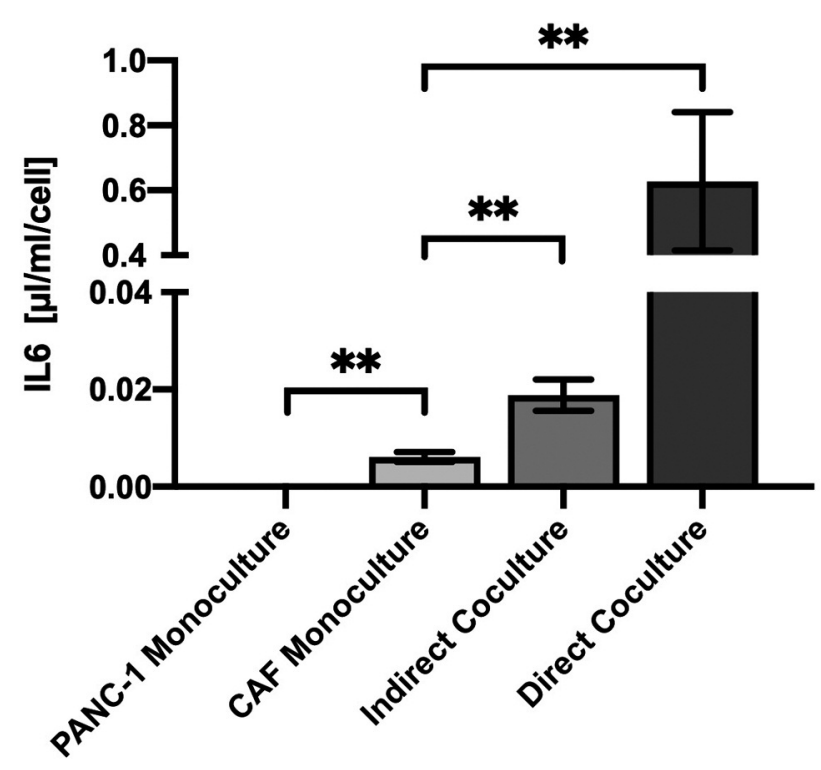

Figure 6. IL6 concentration in the medium supernatant. IL6 concentration was measured in the supernatant of PANC-1 monoculture $(n=3)$, cancer associated fibroblast $(C A F)$ monoculture $(n=3)$, in indirect $(n=4)$ and direct coculture $(n=3)$ of CAFs with PANC-1. PANC-1 did not show any production of IL6. The presence of PANC-1 in the coculture however, induced a significant increase in IL6 production by CAFs.

stroma, systemic hormonal mediators and cytokines are unlikely to reach the tumor cells via the blood stream. Thus, a more local crosstalk must play a predominant role in intercellular communication. To this end, we investigated IL6 , a pro-inflammatory cytokine known to promote migration and metastasis (30). We could verify that CAFs are the major source of IL-6 in the PDAC-CAF axis. PDAC cells did not show IL-6 secretion, while enhanced the capacity of CAFs to produce IL-6, most eminent in direct co-cultures.

The crosstalk between stromal cells and tumor cells has recently been discovered as a potential source of novel therapeutic targets. Preclinical studies investigating the depletion of CAFs revealed promising anti-cancerous effects (59). Yet, this targeted approach remains challenging as the CAFs role in the tumor microenvironment is complex and still under investigation. Depletion even leads to an increase in EMT (60). Therefore, the focus must remain on CAFdependent pro cancerous pathways, such as IL6/STAT3 signaling. The anti-fibrotic tyrosine kinase inhibitor nintedanib was shown to reduce tumor aggressiveness in intrahepatic cholangiocarcinoma via suppression of IL6 and other cytokines (61). Moreover, several novel inhibitors of the IL6/STAT3 pathway, as Stattic (6-Nitrobenzo(b)thiophene-1,1-dioxide) and AZD9150, [a signal transducer and activator of transcription 3 (STAT3) antisense] are being investigated in both, preclinical and early phase clinical studies. In combination with other established chemotherapeutics, a reversed effect of STAT3mediated chemoresistance was documented (62). Napabucasin (2-acetylfuro-1,4-naphthoquinone or BBI-608), an inihibitor of STAT3 signaling, is currently being investigated in a phase III trial together with nab-paclitaxel and gemcitabine for metastatic pancreatic cancer (63). In addition to chemotherapeutics, targeting the IL6/STAT3 pathway is promoted as a feasible therapeutic approach in the advanced tumor stage. However, to specifically target the invasive properties supported by CAFs, further studies investigating the underlying signaling pathways are needed.

\section{Conclusion}

CAFs show the capacity to migrate in vitro and also enhance the migration of PDAC cells. This feature is accompanied by an increase in IL-6 production. Non-cancer associated fibroblasts from established cell lines display none of these properties. We therefore conclude that CAFs are a key element of intra-tumoral migration and should, in this context, be investigated as a potential therapeutic target.

\section{Conflicts of Interest}

The Authors have no conflicts of interest to declare in relation to this study.

\section{Authors' Contributions}

JP, MB, IMS, RBS CCMN and EvH developed the project. EvH performed the experiments. CCMN, EvH, MF and RBS analyzed the results, ARS, EvH, MF, JG and AS contributed to the interpretation of the results. EvH and RBS wrote the paper. MB, MF, IMS, JP ARS, JG and CCMN revised the Paper.

\section{Acknowledgements}

The Authors would like to thank all the patients, physicians and nurses participating in this study. Dr. Rosa Schmuck is a participant in the BIH- Charite Clinician Scientist Program funded by the Charité - Universitätsmedizin Berlin and the Berlin Institute of Health. The Authors appreciate the support of the Leibniz-Institute for the cell line validation (STR-fingerprinting by Dr. Wilhelm Dirks) and also thank Anja Reutzel-Selke, Anja Schirmeier and Bruno Sinn for their support.

\section{References}

1 Siegel RL, Miller KD and Jemal A: Cancer statistics, 2020. CA Cancer J Clin 70(1): 7-30, 2020. PMID: 31912902. DOI: $10.3322 / \mathrm{caac} .21590$

2 Rhim AD, Mirek ET, Aiello NM, Maitra A, Bailey JM, McAllister F, Reichert M, Beatty GL, Rustgi AK, Vonderheide RH, Leach SD and Stanger BZ: EMT and dissemination precede pancreatic tumor formation. Cell 148(1-2): 349-361, 2012. PMID: 22265420. DOI: 10.1016/j.cell.2011.11.025 
3 Aier I, Semwal R, Sharma A and Varadwaj PK: A systematic assessment of statistics, risk factors, and underlying features involved in pancreatic cancer. Cancer Epidemiol 58: 104-110, 2019. PMID: 30537645. DOI: 10.1016/j.canep.2018.12.001

4 Conroy T, Desseigne F, Ychou M, Bouché O, Guimbaud R, Bécouarn Y, Adenis A, Raoul JL, Gourgou-Bourgade S, de la Fouchardière C, Bennouna J, Bachet JB, Khemissa-Akouz F, Péré-Vergé D, Delbaldo C, Assenat E, Chauffert B, Michel P, Montoto-Grillot C, Ducreux M, Groupe Tumeurs Digestives of Unicancer and PRODIGE Intergroup: FOLFIRINOX versus gemcitabine for metastatic pancreatic cancer. N Engl J Med 364(19): 1817-1825, 2011. PMID: 21561347. DOI: 10.1056/ NEJMoa1011923

5 Zhan HX, Zhou B, Cheng YG, Xu JW, Wang L, Zhang GY and Hu SY: Crosstalk between stromal cells and cancer cells in pancreatic cancer: New insights into stromal biology. Cancer Lett 392: 83-93, 2017. PMID: 28189533. DOI: 10.1016/ j.canlet.2017.01.041

6 Nielsen MF, Mortensen MB and Detlefsen S: Key players in pancreatic cancer-stroma interaction: Cancer-associated fibroblasts, endothelial and inflammatory cells. World J Gastroenterol 22(9): 2678-2700, 2016. PMID: 26973408. DOI: 10.3748/wjg.v22.i9.2678

7 Luo G, Long J, Zhang B, Liu C, Xu J, Ni Q and Yu X: Stroma and pancreatic ductal adenocarcinoma: an interaction loop. Biochim Biophys Acta 1826(1): 170-178, 2012. PMID: 22521638. DOI: 10.1016/j.bbcan.2012.04.002

8 Gascard P and Tlsty TD: Carcinoma-associated fibroblasts: orchestrating the composition of malignancy. Genes Dev 30(9): 1002-1019, 2016. PMID: 27151975. DOI: 10.1101/gad.279737.116

9 Jolly LA, Novitskiy S, Owens P, Massoll N, Cheng N, Fang W, Moses HL and Franco AT: Fibroblast-mediated collagen remodeling within the tumor microenvironment facilitates progression of thyroid cancers driven by BrafV600E and Pten loss. Cancer Res 76(7): 1804-1813, 2016. PMID: 26818109. DOI: $10.1158 / 0008-5472 . C A N-15-2351$

10 Demircioglu F, Wang J, Candido J, Costa ASH, Casado P, de Luxan Delgado B, Reynolds LE, Gomez-Escudero J, Newport E, Rajeeve V, Baker AM, Roy-Luzarraga M, Graham TA, Foster J, Wang Y, Campbell JJ, Singh R, Zhang P, Schall TJ, Balkwill FR, Sosabowski J, Cutillas PR, Frezza C, Sancho P and Hodivala-Dilke K: Cancer associated fibroblast FAK regulates malignant cell metabolism. Nat Commun 11(1): 1290, 2020. PMID: 32157087. DOI: 10.1038/s41467-020-15104-3

11 Shan T, Chen S, Chen X, Lin WR, Li W, Ma J, Wu T, Ji H, Li Y, Cui X and Kang Y: Prometastatic mechanisms of CAFmediated EMT regulation in pancreatic cancer cells. Int J Oncol 50(1): 121-128, 2017. PMID: 27878234. DOI: 10.3892/ ijo.2016.3779

12 Pietras K and Ostman A: Hallmarks of cancer: interactions with the tumor stroma. Exp Cell Res 316(8): 1324-1331, 2010. PMID: 20211171. DOI: 10.1016/j.yexcr.2010.02.045

13 Shan T, Chen S, Chen X, Lin WR, Li W, Ma J, Wu T, Cui X, Ji $\mathrm{H}$, Li Y and Kang Y: Cancer-associated fibroblasts enhance pancreatic cancer cell invasion by remodeling the metabolic conversion mechanism. Oncol Rep 37(4): 1971-1979, 2017. PMID: 28260082. DOI: 10.3892/or.2017.5479

14 Kalluri R and Zeisberg M: Fibroblasts in cancer. Nat Rev Cancer 6(5): 392-401, 2006. PMID: 16572188. DOI: 10.1038/nrc 1877
15 Kadaba R, Birke H, Wang J, Hooper S, Andl CD, Di Maggio F, Soylu E, Ghallab M, Bor D, Froeling FE, Bhattacharya S, Rustgi AK, Sahai E, Chelala C, Sasieni P and Kocher HM: Imbalance of desmoplastic stromal cell numbers drives aggressive cancer processes. J Pathol 230(1): 107-117, 2013. PMID: 23359139. DOI: $10.1002 /$ path.4172

16 Kalluri R: The biology and function of fibroblasts in cancer. Nat Rev Cancer 16(9): 582-598, 2016. PMID: 27550820. DOI: $10.1038 /$ nrc. 2016.73

17 Quail DF and Joyce JA: Microenvironmental regulation of tumor progression and metastasis. Nat Med 19(11): 1423-1437, 2013. PMID: 24202395. DOI: 10.1038/nm.3394

18 Apte MV, Xu Z, Pothula S, Goldstein D, Pirola RC and Wilson JS: Pancreatic cancer: The microenvironment needs attention too! Pancreatology 15(4 Suppl): S32-S38, 2015. PMID: 25845856. DOI: 10.1016/j.pan.2015.02.013

19 Heneberg P: Paracrine tumor signaling induces transdifferentiation of surrounding fibroblasts. Crit Rev Oncol Hematol 97: 303-311, 2016. PMID: 26467073. DOI: 10.1016/j.critrevonc.2015.09.008

20 Moir JA, Mann J and White SA: The role of pancreatic stellate cells in pancreatic cancer. Surg Oncol 24(3): 232-238, 2015. PMID: 26080604. DOI: 10.1016/j.suronc.2015.05.002

21 Bolm L, Cigolla S, Wittel UA, Hopt UT, Keck T, Rades D, Bronsert $\mathrm{P}$ and Wellner UF: The role of fibroblasts in pancreatic cancer: Extracellular matrix versus paracrine factors. Transl Oncol 10(4): 578-588, 2017. PMID: 28658650. DOI: 10.1016/j.tranon.2017.04.009

22 Guan J, Zhang H, Wen Z, Gu Y, Cheng Y, Sun Y, Zhang T, Jia $\mathrm{C}, \mathrm{Lu} \mathrm{Z}$ and Chen J: Retinoic acid inhibits pancreatic cancer cell migration and EMT through the downregulation of IL-6 in cancer associated fibroblast cells. Cancer Lett 345(1): 132-139, 2014. PMID: 24334138. DOI: 10.1016/j.canlet.2013.12.006

23 Roshani R, McCarthy F and Hagemann T: Inflammatory cytokines in human pancreatic cancer. Cancer Lett 345(2): 157163, 2014. PMID: 23879960. DOI: 10.1016/j.canlet.2013.07.014

24 Hu B, Zhang K, Li S, Li H, Yan Z, Huang L, Wu J, Han X, Jiang W, Mulatibieke T, Zheng L, Wan R, Wang X and Hu G: HIC1 attenuates invasion and metastasis by inhibiting the IL-6/STAT3 signalling pathway in human pancreatic cancer. Cancer Lett 376(2): 387-398, 2016. PMID: 27085461. DOI: 10.1016/ j.canlet.2016.04.013

25 Lesina M, Kurkowski MU, Ludes K, Rose-John S, Treiber M, Klöppel G, Yoshimura A, Reindl W, Sipos B, Akira S, Schmid $\mathrm{RM}$ and Algül $\mathrm{H}$ : Stat $3 /$ Socs 3 activation by IL-6 transsignaling promotes progression of pancreatic intraepithelial neoplasia and development of pancreatic cancer. Cancer Cell 19(4): 456-469, 2011. PMID: 21481788. DOI: 10.1016/j.ccr.2011.03.009

26 Nagathihalli NS, Castellanos JA, VanSaun MN, Dai X, Ambrose M, Guo Q, Xiong Y and Merchant NB: Pancreatic stellate cell secreted IL-6 stimulates STAT3 dependent invasiveness of pancreatic intraepithelial neoplasia and cancer cells. Oncotarget 7(40): 65982-65992, 2016. PMID: 27602757. DOI: 10.18632/oncotarget.11786

27 Wu Q, Tian Y, Zhang J, Zhang H, Gu F, Lu Y, Zou S, Chen Y, Sun P, Xu M, Sun X, Xia C, Chi H, Ying Zhu A, Tang D and Wang D: Functions of pancreatic stellate cell-derived soluble factors in the microenvironment of pancreatic ductal carcinoma. Oncotarget 8(60): 102721-102738, 2017. PMID: 29254283. DOI: $10.18632 /$ oncotarget.21970 
$28 \mathrm{Wu}$ YS, Chung I, Wong WF, Masamune A, Sim MS and Looi CY: Paracrine IL-6 signaling mediates the effects of pancreatic stellate cells on epithelial-mesenchymal transition via Stat3/Nrf2 pathway in pancreatic cancer cells. Biochim Biophys Acta Gen Subj 1861(2): 296-306, 2017. PMID: 27750041. DOI: 10.1016/j.bbagen.2016.10.006

29 Zhang Y, Yan W, Collins MA, Bednar F, Rakshit S, Zetter BR, Stanger BZ, Chung I, Rhim AD and di Magliano MP: Interleukin- 6 is required for pancreatic cancer progression by promoting MAPK signaling activation and oxidative stress resistance. Cancer Res 73(20): 6359-6374, 2013. PMID: 24097820. DOI: 10.1158/0008-5472.CAN-13-1558-T

30 Razidlo GL, Burton KM and McNiven MA: Interleukin-6 promotes pancreatic cancer cell migration by rapidly activating the small GTPase CDC42. J Biol Chem 293(28): 11143-11153, 2018. PMID: 29853638. DOI: 10.1074/jbc.RA118.003276

31 Pop VV, Seicean A, Lupan I, Samasca G and Burz CC: IL-6 roles - Molecular pathway and clinical implication in pancreatic cancer - A systemic review. Immunol Lett 181: 45-50, 2017. PMID: 27876525. DOI: 10.1016/j.imlet.2016.11.010

32 Friedl $\mathrm{P}$ and Gilmour D: Collective cell migration in morphogenesis, regeneration and cancer. Nat Rev Mol Cell Biol 10(7): 445-457, 2009. PMID: 19546857. DOI: $10.1038 / \mathrm{nrm} 2720$

33 Hill R, Song Y, Cardiff RD and Van Dyke T: Selective evolution of stromal mesenchyme with p53 loss in response to epithelial tumorigenesis. Cell 123(6): 1001-1011, 2005. PMID: 16360031. DOI: $10.1016 /$ j.cell.2005.09.030

34 Bianchi-Frias D, Basom R, Delrow JJ, Coleman IM, Dakhova O, Qu X, Fang M, Franco OE, Ericson NG, Bielas JH, Hayward SW, True L, Morrissey C, Brown L, Bhowmick NA, Rowley D, Ittmann $\mathrm{M}$ and Nelson PS: Cells comprising the prostate cancer microenvironment lack recurrent clonal somatic genomic aberrations. Mol Cancer Res 14(4): 374-384, 2016. PMID: 26753621. DOI: 10.1158/1541-7786.MCR-15-0330

35 Arandkar S, Furth N, Elisha Y, Nataraj NB, van der Kuip H, Yarden Y, Aulitzky W, Ulitsky I, Geiger B and Oren M: Altered p53 functionality in cancer-associated fibroblasts contributes to their cancer-supporting features. Proc Natl Acad Sci USA 115(25): 6410-6415, 2018. PMID: 29866855. DOI: $10.1073 /$ pnas. 1719076115

36 Moskovits N, Kalinkovich A, Bar J, Lapidot T and Oren M: p53 Attenuates cancer cell migration and invasion through repression of SDF-1/CXCL12 expression in stromal fibroblasts. Cancer Res 66(22): 10671-10676, 2006. PMID: 17108103. DOI 10.1158/0008-5472.CAN-06-2323

37 Hahn WC, Counter CM, Lundberg AS, Beijersbergen RL, Brooks MW and Weinberg RA: Creation of human tumour cells with defined genetic elements. Nature 400(6743): 464-468, 1999. PMID: 10440377 . DOI: $10.1038 / 22780$

38 Neumann CCM, von Hörschelmann E, Reutzel-Selke A, Seidel E, Sauer IM, Pratschke J, Bahra M and Schmuck RB: Tumorstromal cross-talk modulating the therapeutic response in pancreatic cancer. Hepatobiliary Pancreat Dis Int 17(5): 461-472, 2018. PMID: 30243879. DOI: 10.1016/j.hbpd.2018.09.004

39 Fujita H, Ohuchida K, Mizumoto K, Egami T, Miyoshi K, Moriyama T, Cui L, Yu J, Zhao M, Manabe T and Tanaka M: Tumor-stromal interactions with direct cell contacts enhance proliferation of human pancreatic carcinoma cells. Cancer Sci 100(12): 2309-2317, 2009. PMID: 19735487. DOI: 10.1111/j.1349-7006.2009.01317.x
40 Shen J, Najafi S, Stäble S, Fabian J, Koeneke E, Kolbinger FR, Wrobel JK, Meder B, Distel M, Heimburg T, Sippl W, Jung M, Peterziel H, Kranz D, Boutros M, Westermann F, Witt O and Oehme I: A kinome-wide RNAi screen identifies ALK as a target to sensitize neuroblastoma cells for HDAC8-inhibitor treatment. Cell Death Differ 25(12): 2053-2070, 2018. PMID: 29515255. DOI: $10.1038 / \mathrm{s} 41418-018-0080-0$

41 Schindelin J, Arganda-Carreras I, Frise E, Kaynig V, Longair M, Pietzsch T, Preibisch S, Rueden C, Saalfeld S, Schmid B, Tinevez JY, White DJ, Hartenstein V, Eliceiri K, Tomancak P and Cardona A: Fiji: an open-source platform for biologicalimage analysis. Nat Methods 9(7): 676-682, 2012. PMID: 22743772. DOI: $10.1038 /$ nmeth.2019

42 Bosch M: Introduction to ImageJ macro language in a particle counting analysis: automation matters. Methods Mol Biol 2040: 5170, 2019. PMID: 31432475. DOI: 10.1007/978-1-4939-9686-5_4

43 Pereira BA, Vennin C, Papanicolaou M, Chambers CR, Herrmann D, Morton JP, Cox TR and Timpson P: CAF Subpopulations: A new reservoir of stromal targets in pancreatic cancer. Trends Cancer 5(11): 724-741, 2019. PMID: 31735290. DOI: $10.1016 /$ j.trecan.2019.09.010

44 Gieniec KA, Butler LM, Worthley DL and Woods SL: Cancerassociated fibroblasts-heroes or villains? Br J Cancer 121(4): 293-302, 2019. PMID: 31289350. DOI: 10.1038/s41416-0190509-3

45 Franco OE, Shaw AK, Strand DW and Hayward SW: Cancer associated fibroblasts in cancer pathogenesis. Semin Cell Dev Biol 21(1): 33-39, 2010. PMID: 19896548. DOI: 10.1016/j.semcdb.2009.10.010

$46 \mathrm{Lu} \mathrm{L}$ and Zeng J: Evaluation of K-ras and p53 expression in pancreatic adenocarcinoma using the cancer genome atlas. PLoS One 12(7): e0181532, 2017. PMID: 28742845. DOI: 10.1371/ journal.pone. 0181532

47 Addadi Y, Moskovits N, Granot D, Lozano G, Carmi Y, Apte RN, Neeman M and Oren M: p53 status in stromal fibroblasts modulates tumor growth in an SDF1-dependent manner. Cancer Res 70(23): 9650-9658, 2010. PMID: 20952507. DOI: 10.1158/0008-5472.CAN-10-1146

48 Liu Q, Yu B, Tian Y, Dan J, Luo Y and Wu X: P53 Mutant p53 N236S regulates cancer-associated fibroblasts properties through Stat3 pathway. Onco Targets Ther 13: 1355-1363, 2020. PMID: 32104002. DOI: 10.2147/OTT.S229065

49 Schmid JO, Dong M, Haubeiss S, Friedel G, Bode S, Grabner A, Ott G, Mürdter TE, Oren M, Aulitzky WE and van der Kuip H: Cancer cells cue the p53 response of cancerassociated fibroblasts to cisplatin. Cancer Res 72(22): 58245832, 2012. PMID: 22962266. DOI: 10.1158/0008-5472.CAN$12-1201$

50 Hingorani SR, Wang L, Multani AS, Combs C, Deramaudt TB, Hruban RH, Rustgi AK, Chang $S$ and Tuveson DA: Trp53R172H and KrasG12D cooperate to promote chromosomal instability and widely metastatic pancreatic ductal adenocarcinoma in mice. Cancer Cell 7(5): 469-483, 2005. PMID: 15894267. DOI: 10.1016/j.ccr.2005.04.023

51 Sato M, Larsen JE, Lee W, Sun H, Shames DS, Dalvi MP, Ramirez RD, Tang H, DiMaio JM, Gao B, Xie Y, Wistuba II, Gazdar AF, Shay JW and Minna JD: Human lung epithelial cells progressed to malignancy through specific oncogenic manipulations. Mol Cancer Res 11(6): 638-650, 2013. PMID: 23449933. DOI: 10.1158/1541-7786.MCR-12-0634-T 
52 Kamisawa T, Wood LD, Itoi T and Takaori K: Pancreatic cancer. Lancet 388(10039): 73-85, 2016. PMID: 26830752. DOI: 10.1016/S0140-6736(16)00141-0

53 Dunn KL, He S, Wark L, Delcuve GP, Sun JM, Yu Chen H, Mai $\mathrm{S}$ and Davie JR: Increased genomic instability and altered chromosomal protein phosphorylation timing in HRAStransformed mouse fibroblasts. Genes Chromosomes Cancer 48(5): 397-409, 2009. PMID: 19191262. DOI: 10.1002/gcc.20649

54 Horsch M, Recktenwald CV, Schädler S, Hrabé de Angelis M, Seliger B and Beckers J: Overexpressed vs mutated Kras in murine fibroblasts: a molecular phenotyping study. Br J Cancer 100(4): 656-662, 2009. PMID: 19190631. DOI: 10.1038/sj.bjc.6604882

55 Dauer P, Zhao X, Gupta VK, Sharma N, Kesh K, Gnamlin P, Dudeja V, Vickers SM, Banerjee S and Saluja A: Inactivation of cancer-associated-fibroblasts disrupts oncogenic signaling in pancreatic cancer cells and promotes its regression. Cancer Res 78(5): 1321-1333, 2018. PMID: 29259015. DOI: 10.1158/00085472.CAN-17-2320

56 Feig C, Gopinathan A, Neesse A, Chan DS, Cook N and Tuveson DA: The pancreas cancer microenvironment. Clin Cancer Res 18(16): 4266-4276, 2012. PMID: 22896693. DOI: 10.1158/1078-0432.CCR-11-3114

57 Erdogan B, Ao M, White LM, Means AL, Brewer BM, Yang L, Washington MK, Shi C, Franco OE, Weaver AM, Hayward SW, Li D and Webb DJ: Cancer-associated fibroblasts promote directional cancer cell migration by aligning fibronectin. J Cell Biol 216(11): 3799-3816, 2017. PMID: 29021221. DOI: $10.1083 /$ jcb.201704053

58 Conklin MW, Eickhoff JC, Riching KM, Pehlke CA, Eliceiri KW, Provenzano PP, Friedl A and Keely PJ: Aligned collagen is a prognostic signature for survival in human breast carcinoma. Am J Pathol 178(3): 1221-1232, 2011. PMID: 21356373. DOI: 10.1016/j.ajpath.2010.11.076
59 Chen $\mathrm{X}$ and Song E: Turning foes to friends: targeting cancerassociated fibroblasts. Nat Rev Drug Discov 18(2): 99-115, 2019. PMID: 30470818. DOI: 10.1038/s41573-018-0004-1

60 Rhim AD, Oberstein PE, Thomas DH, Mirek ET, Palermo CF, Sastra SA, Dekleva EN, Saunders T, Becerra CP, Tattersall IW, Westphalen CB, Kitajewski J, Fernandez-Barrena MG, Fernandez-Zapico ME, Iacobuzio-Donahue C, Olive KP and Stanger BZ: Stromal elements act to restrain, rather than support, pancreatic ductal adenocarcinoma. Cancer Cell 25(6): 735-747, 2014. PMID: 24856585. DOI: 10.1016/j.ccr.2014.04.021

61 Yamanaka T, Harimoto N, Yokobori T, Muranushi R, Hoshino K, Hagiwara K, Gantumur D, Handa T, Ishii N, Tsukagoshi M, Igarashi T, Tanaka H, Watanabe A, Kubo N, Araki K and Shirabe $\mathrm{K}$ : Nintedanib inhibits intrahepatic cholangiocarcinoma aggressiveness via suppression of cytokines extracted from activated cancer-associated fibroblasts. Br J Cancer 122(7): 986994, 2020. PMID: 32015511. DOI: 10.1038/s41416-020-0744-7

62 Huang TX, Guan XY and Fu L: Therapeutic targeting of the crosstalk between cancer-associated fibroblasts and cancer stem cells. Am J Cancer Res 9(9): 1889-1904, 2019. PMID: 31598393.

63 Sonbol MB, Ahn DH, Goldstein D, Okusaka T, Tabernero J, Macarulla T, Reni M, Li CP, O'Neil B, Van Cutsem E and Bekaii-Saab T: CanStem111P trial: a Phase III study of napabucasin plus nab-paclitaxel with gemcitabine. Future Oncol 15(12): 1295-1302, 2019. PMID: 30768369. DOI: 10.2217/fon2018-0903 